\title{
Kudriasov Type Univalence Criteria for Some Integral Operators
}

\author{
Virgil Pescar ${ }^{1}$ and Nicoleta Breaz ${ }^{2}$ \\ ${ }^{1}$ Department of Mathematics and Computer Science, Faculty of Mathematics and Computer Science, Transilvania University of Braşov, \\ 500091 Braşov, Romania \\ ${ }^{2}$ Department of Mathematics and Computer Science, Faculty of Science, "1 Decembrie 1918" University of Alba Iulia, \\ 510009 Alba, Romania
}

Correspondence should be addressed to Nicoleta Breaz; nicoletabreaz@yahoo.com

Received 30 September 2013; Accepted 4 December 2013

Academic Editor: Mohamed Kamal Aouf

Copyright ( $) 2013$ V. Pescar and N. Breaz. This is an open access article distributed under the Creative Commons Attribution License, which permits unrestricted use, distribution, and reproduction in any medium, provided the original work is properly cited.

We consider some integral operators defined by analytic functions in the open unit disk and derive new univalence criteria for these operators, using Kudriasov condition for a function to be univalent.

\section{Introduction}

Let $\mathscr{A}$ be the class of functions $f$ which are analytic in the open unit $\operatorname{disk} U=\{z \in \mathbb{C}:|z|<1\}$ of the form

$$
f(z)=z+\sum_{n=2}^{\infty} a_{n} z^{n}
$$

normalized by $f(0)=f^{\prime}(0)-1=0$.

We denote by $\mathcal{S}$ the subclass of $\mathscr{A}$ consisting of functions $f \in \mathscr{A}$, which are univalent in $U$.

We consider the integral operators

$$
\begin{gathered}
H_{n}(z)=\left\{\beta \int_{0}^{z} u^{\beta-1}\left(\frac{f_{1}(u)}{u}\right)^{\gamma_{1}} \cdots\left(\frac{f_{n}(u)}{u}\right)^{\gamma_{n}} d u\right\}^{1 / \beta}, \\
T_{n}(z)=\left\{\beta \int_{0}^{z} u^{\beta-1}\left(f_{1}^{\prime}(u)\right)^{\gamma_{1}} \cdots\left(f_{n}^{\prime}(u)\right)^{\gamma_{n}} d u\right\}^{1 / \beta},
\end{gathered}
$$

for $\beta, \gamma_{j}$ being complex numbers, $\beta \neq 0, j=\overline{1, n}$, and the functions $f_{j} \in \mathscr{A}, j=\overline{1, n}$.

Some univalence criteria for these integral operators were studied in [1]. Applying univalence conditions given by Kudriasov [2] and Pascu [3], we obtain new Kudriasov type univalence criteria for these two integral operators.

\section{Preliminaries}

Various generalizations of Becker's univalence criteria for analytic functions given in [4] were obtained by many authors. For example, the result obtained by Pascu in [3] is also known as an improvement of Becker's univalence criteria. This result or other similar generalizations of Becker's univalence criteria have been used further to derive new univalence criteria for integral operators (see, e.g., some relatively recent works as $[1,5,6])$. In this paper we use Pascu improvement of Becker's univalence criteria and also another univalence condition for a function to be univalent, given by Kudriasov in [2]. There are also some papers devoted to univalence criteria that use some Kudriasov type conditions (see, e.g., the work [1] containing a chapter dedicated to Kudriasov type univalence conditions and other papers as, e.g., $[7-10])$.

The following univalence criteria are given by Kudriasov for a regular function.

Lemma 1 (see [2]). Let $f$ be a regular function in $U, f(z)=z+$ $a_{2} z^{2}+\cdots$. If

$$
\left|\frac{f^{\prime \prime}(z)}{f^{\prime}(z)}\right| \leq K, \quad z \in U,
$$

for all $z \in U$, where $K \cong 3.05$, the function $f$ is univalent in $U$. 
Remark 2. The constant $K$ is a solution of the equation $8\left[x(x-2)^{3}\right]^{1 / 2}-3(4-x)^{2}=12$. An approximation of this solution in MATLAB environment is 3.03902118847875 . However, we call this constant in our further results like Kudriasov gave it, approximately equal to 3.05.

The improvement of Becker's univalence condition is given by Pascu for integral operators as follows.

Lemma 3 (see [3]). Let $\alpha$ be a complex number, $\operatorname{Re} \alpha>0$, and the function $f \in \mathscr{A}$. If

$$
\frac{1-|z|^{2 \operatorname{Re} \alpha}}{\operatorname{Re} \alpha}\left|\frac{z f^{\prime \prime}(z)}{f^{\prime}(z)}\right| \leq 1
$$

for all $z \in U$, then for every complex number $\beta, \operatorname{Re} \beta \geq \operatorname{Re} \alpha$, the function

$$
F_{\beta}(z)=\left[\beta \int_{0}^{z} u^{\beta-1} f^{\prime}(u) d u\right]^{1 / \beta}
$$

is regular and univalent in $U$.

\section{Main Results}

Theorem 4. Let $\alpha, \gamma_{j}$ be complex numbers, $\operatorname{Re} \alpha>0, j=\overline{1, n}$, the functions $f_{j} \in \mathscr{A}, f_{j}=z+a_{2 j} z^{2}+\cdots, j=\overline{1, n}, n \in \mathbb{N}-\{0\}$, and $K$ the positive real number $K \cong 3.05$.

If

$$
\begin{gathered}
\left|\frac{f_{j}^{\prime \prime}(z)}{f_{j}^{\prime}(z)}\right| \leq K, \quad z \in U, j=\overline{1, n}, \\
\left|\gamma_{1}\right|+\left|\gamma_{2}\right|+\cdots+\left|\gamma_{n}\right| \leq \min \left\{\frac{\operatorname{Re} \alpha}{4}, \frac{1}{4}\right\},
\end{gathered}
$$

then $f_{j} \in \mathcal{S}, j=\overline{1, n}$, and for every complex number $\beta, \operatorname{Re} \beta \geq$ $\operatorname{Re} \alpha$, the integral operator $H_{n}$ is in the class $\mathcal{S}$.

Proof. Let us consider the function

$$
h_{n}(z)=\int_{0}^{z}\left(\frac{f_{1}(u)}{u}\right)^{\gamma_{1}} \cdots\left(\frac{f_{n}(u)}{u}\right)^{\gamma_{n}} d u
$$

The function $h_{n}$ is regular in $U$ and $h_{n}(0)=h_{n}^{\prime}(0)-1=0$. We have

$$
\frac{z h_{n}^{\prime \prime}(z)}{h_{n}^{\prime}(z)}=\gamma_{1}\left(\frac{z f_{1}^{\prime}(z)}{f_{1}(z)}-1\right)+\cdots+\gamma_{n}\left(\frac{z f_{n}^{\prime}(z)}{f_{n}(z)}-1\right),
$$

for all $z \in U$.

From (9), we obtain further

$$
\begin{aligned}
\left|\frac{z h_{n}^{\prime \prime}(z)}{h_{n}^{\prime}(z)}\right| \leq & \left|\gamma_{1}\right|\left(\left|\frac{z f_{1}^{\prime}(z)}{f_{1}(z)}\right|+1\right) \\
& +\cdots+\left|\gamma_{n}\right|\left(\left|\frac{z f_{n}^{\prime}(z)}{f_{n}(z)}\right|+1\right) .
\end{aligned}
$$

By (6) and Lemma 1 , we have $f_{j} \in \mathcal{S}, j=\overline{1, n}$, and hence we obtain

$$
\left|\frac{z f_{j}^{\prime}(z)}{f_{j}(z)}\right| \leq \frac{1+|z|}{1-|z|}, \quad z \in U, j=\overline{1, n}
$$

From (10) and (11), we get

$$
\frac{1-|z|^{2 \operatorname{Re} \alpha}}{\operatorname{Re} \alpha}\left|\frac{z h_{n}^{\prime \prime}(z)}{h_{n}^{\prime}(z)}\right| \leq \frac{1-|z|^{2 \operatorname{Re} \alpha}}{\operatorname{Re} \alpha} \frac{2}{1-|z|}\left(\left|\gamma_{1}\right|+\cdots+\left|\gamma_{n}\right|\right)
$$

for all $z \in U$.

Now we consider the following cases.

(1) $0<\operatorname{Re} \alpha<1$. The function $s:(0,1) \rightarrow \mathbb{R}, s(x)=$ $1-a^{2 x}, x=\operatorname{Re} \alpha, a=|z|,(0 \leq a<1)$ is increasing and we obtain

$$
1-|z|^{2 \operatorname{Re} \alpha} \leq 1-|z|^{2}, \quad z \in U
$$

From (12) and (13), we obtain

$$
\frac{1-|z|^{2 \operatorname{Re} \alpha}}{\operatorname{Re} \alpha}\left|\frac{z h_{n}^{\prime \prime}(z)}{h_{n}^{\prime}(z)}\right| \leq \frac{4}{\operatorname{Re} \alpha}\left(\left|\gamma_{1}\right|+\cdots+\left|\gamma_{n}\right|\right)
$$

for all $z \in U$.

Using the hypothesis condition (7), from (14), we have

$$
\frac{1-|z|^{2 \operatorname{Re} \alpha}}{\operatorname{Re} \alpha}\left|\frac{z h_{n}^{\prime \prime}(z)}{h_{n}^{\prime}(z)}\right| \leq 1,
$$

for all $z \in U$.

(2) $\operatorname{Re} \alpha \geq 1$. We notice that the function

$$
\begin{aligned}
& q:[1, \infty) \longrightarrow \mathbb{R}, \quad q(x)=\frac{1-a^{2 x}}{x}, \\
& x=\operatorname{Re} \alpha, \quad a=|z|, \quad(0 \leq a<1)
\end{aligned}
$$

is decreasing function, and we obtain

$$
\frac{1-|z|^{2 \operatorname{Re} \alpha}}{\operatorname{Re} \alpha} \leq 1-|z|^{2}, \quad z \in U .
$$

Using the last inequality in (12), we have

$$
\frac{1-|z|^{2 \operatorname{Re} \alpha}}{\operatorname{Re} \alpha}\left|\frac{z h_{n}^{\prime \prime}(z)}{h_{n}^{\prime}(z)}\right| \leq 4\left(\left|\gamma_{1}\right|+\cdots+\left|\gamma_{n}\right|\right)
$$

for all $z \in U$.

Now using the hypothesis condition (7), from (18), we get

$$
\frac{1-|z|^{2 \operatorname{Re} \alpha}}{\operatorname{Re} \alpha}\left|\frac{z h_{n}^{\prime \prime}(z)}{h_{n}^{\prime}(z)}\right| \leq 1
$$

for all $z \in U$.

Hence, based on the conditions obtained in (15) and in (19), applying Lemma 3, we have that $H_{n} \in \mathcal{S}$. 
Theorem 5. Let $\alpha, \gamma_{j}$ be complex numbers, $j=\overline{1, n}$, $\operatorname{Re} \alpha>0$, the functions $f_{j} \in \mathscr{A}, f_{j}(z)=z+a_{2 j} z^{2}+\cdots, j=\overline{1, n}, n \in$ $\mathbb{N}-\{0\}$, and $K$ the positive real number, $K \cong 3.05$.

If

$$
\begin{gathered}
\left|\frac{f_{j}^{\prime \prime}(z)}{f_{j}^{\prime}(z)}\right| \leq K, \quad z \in U, j=\overline{1, n}, \\
\left|\gamma_{1}\right|+\left|\gamma_{2}\right|+\cdots+\left|\gamma_{n}\right| \leq \frac{(2 \operatorname{Re} \alpha+1)^{(2 \operatorname{Re} \alpha+1) /(2 \operatorname{Re} \alpha)}}{2 K},
\end{gathered}
$$

then $f_{j} \in \mathcal{S}, j=\overline{1, n}$, and for every complex number $\beta, \operatorname{Re} \beta \geq$ $\operatorname{Re} \alpha$, the integral operator $T_{n}$ is in the class $\mathcal{S}$.

Proof. By (20) and Lemma 1, we obtain that $f_{j} \in \mathcal{S}, j=\overline{1, n}$. We consider the function

$$
p_{n}(z)=\int_{0}^{z}\left(f_{1}^{\prime}(u)\right)^{\gamma_{1}} \cdots\left(f_{n}^{\prime}(u)\right)^{\gamma_{n}} d u
$$

The function $p_{n}$ is regular in $U$ and $p_{n}(0)=p_{n}^{\prime}(0)-1=0$.

We have

$$
\frac{z p_{n}^{\prime \prime}(z)}{p_{n}^{\prime}(z)}=\gamma_{1} \frac{z f_{1}^{\prime \prime}(z)}{f_{1}^{\prime}(z)}+\cdots+\gamma_{n} \frac{z f_{n}^{\prime \prime}(z)}{f_{n}^{\prime}(z)}
$$

for all $z \in U$.

Further we obtain

$$
\begin{aligned}
& \frac{1-|z|^{2 \operatorname{Re} \alpha}}{\operatorname{Re} \alpha}\left|\frac{z p_{n}^{\prime \prime}(z)}{p_{n}^{\prime}(z)}\right| \\
& \leq \frac{1-|z|^{2 \operatorname{Re} \alpha}}{\operatorname{Re} \alpha}|z|\left[\left|\gamma_{1}\right|\left|\frac{f_{1}^{\prime \prime}(z)}{f_{1}^{\prime}(z)}\right|+\cdots+\left|\gamma_{n}\right|\left|\frac{f_{n}^{\prime \prime}(z)}{f_{n}^{\prime}(z)}\right|\right]
\end{aligned}
$$

From (24) and from the Kudriasov condition within the hypothesis, (20), we have

$$
\begin{aligned}
\frac{1-|z|^{2 \operatorname{Re} \alpha}}{\operatorname{Re} \alpha}\left|\frac{z p_{n}^{\prime \prime}(z)}{p_{n}^{\prime}(z)}\right| \leq & {\left[\frac{1-|z|^{2 \operatorname{Re} \alpha}}{\operatorname{Re} \alpha}|z|\right] } \\
& \times\left(K\left|\gamma_{1}\right|+\cdots+K\left|\gamma_{n}\right|\right),
\end{aligned}
$$

for all $z \in U$.

Let us consider the function $G:[0,1] \rightarrow \mathbb{R}, G(x)=$ $\left(\left(1-x^{2 a}\right) / a\right) x, x=|z|, a=\operatorname{Re} \alpha$. We have

$$
\max _{x \in[0,1]} G(x)=\frac{2}{(2 a+1)^{(2 a+1) /(2 a)}} .
$$

By (25), (26), and (21) we obtain

$$
\frac{1-|z|^{2 \operatorname{Re} \alpha}}{\operatorname{Re} \alpha}\left|\frac{z p_{n}^{\prime \prime}(z)}{p_{n}^{\prime}(z)}\right|<1
$$

for all $z \in U$.

Now from (27) and Lemma 3, it results that $T_{n} \in \mathcal{S}$.

\section{Corollaries}

Corollary 1. Let $\gamma$ be complex number, $\operatorname{Re}[n(\gamma-1)+1]>0$, the functions $f_{j} \in \mathscr{A}, j=\overline{1, n}, n \in \mathbb{N}-\{0\}$, and $K$ the positive real number, $K \cong 3.05$.

If

$$
\begin{gathered}
\left|\frac{f_{j}^{\prime \prime}(z)}{f_{j}^{\prime}(z)}\right| \leq K, \quad z \in U, j=\overline{1, n}, \\
n|\gamma-1| \leq \min \left\{\frac{\operatorname{Re}[n(\gamma-1)+1]}{4}, \frac{1}{4}\right\},
\end{gathered}
$$

then $f_{j} \in \mathcal{S}, j=\overline{1, n}$, and the integral operator $I_{\alpha, n}$ defined by $I_{\alpha, n}(z)=\left\{[n(\gamma-1)+1] \int_{0}^{z} f_{1}^{\gamma-1}(u) \cdots f_{n}^{\gamma-1}(u) d u\right\}^{1 /(n(\gamma-1)+1)}$

is in the class $\mathcal{S}$.

Proof. From (29), we have

$$
\begin{gathered}
I_{\alpha, n}(z)=\left\{[n(\gamma-1)+1] \int_{0}^{z} u^{n(\gamma-1)}\left(\frac{f_{1}(u)}{u}\right)^{\gamma-1}\right. \\
\left.\cdots\left(\frac{f_{n}(u)}{u}\right)^{\gamma-1} d u\right\}^{1 /(n(\gamma-1)+1)},
\end{gathered}
$$

and for $\alpha=\beta=n(\gamma-1)+1, \gamma_{1}=\gamma_{2}=\cdots=\gamma_{n}=\gamma-1$, from Theorem 4, we obtain Corollary 1 .

Corollary 2. Let $\alpha, \gamma_{j}$ be complex numbers, $j=\overline{1, n}, 0<$ $\operatorname{Re} \alpha \leq 1$, the functions $f_{j} \in \mathscr{A}, f_{j}(z)=z+a_{2 j} z^{2}+\cdots$, $j=\overline{1, n}, n \in \mathbb{N}-\{0\}$, and $K$ the positive real number $K \cong 3.05$. If

$$
\begin{gathered}
\left|\frac{f_{j}^{\prime \prime}(z)}{f_{j}^{\prime}(z)}\right| \leq K, \quad z \in U, j=\overline{1, n}, \\
\left|\gamma_{1}\right|+\left|\gamma_{2}\right|+\cdots+\left|\gamma_{n}\right| \leq \frac{\operatorname{Re} \alpha}{4},
\end{gathered}
$$

then $f_{j} \in \mathcal{S}, j=\overline{1, n}$ and the integral operator $L_{n}$ defined by

$$
L_{n}(z)=\int_{0}^{z}\left(\frac{f_{1}(u)}{u}\right)^{\gamma_{1}} \cdots\left(\frac{f_{n}(u)}{u}\right)^{\gamma_{n}} d u
$$

belongs to the class $\mathcal{S}$.

Corollary 3. Let $\alpha, \gamma_{j}$ be complex numbers, $j=\overline{1, n}, 0<$ $\operatorname{Re} \alpha \leq 1$, the functions $f_{j} \in \mathscr{A}, f_{j}(z)=z+a_{2 j} z^{2}+\cdots$, $j=\overline{1, n}, n \in \mathbb{N}-\{0\}$, and $K$ the positive real number, $K \cong 3.05$. If

$$
\left|\frac{f_{j}^{\prime \prime}(z)}{f_{j}^{\prime}(z)}\right| \leq K, \quad z \in U, j=\overline{1, n}
$$

$$
\left|\gamma_{1}\right|+\left|\gamma_{2}\right|+\cdots+\left|\gamma_{n}\right| \leq \frac{(2 \operatorname{Re} \alpha+1)^{(2 \operatorname{Re} \alpha+1) /(2 \operatorname{Re} \alpha)}}{2 K}
$$


then $f_{j} \in \mathcal{S}, j=\overline{1, n}$, and the integral operator $G_{n}$ defined by

$$
G_{n}(z)=\int_{0}^{z}\left(f_{1}^{\prime}(u)\right)^{\gamma_{1}} \cdots\left(f_{n}^{\prime}(u)\right)^{\gamma_{n}} d u
$$

is in the class $\mathcal{S}$.

\section{References}

[1] V. Pescar and V. D. Breaz, The Univalence of Integral Operators, Academic Publishing House, Sofia, Bulgaria, 2008.

[2] N. S. Kudriasov, "Onekotorîh priznakah odnolistnosti analiticeschih funktii," Matematiceskie Zametki, vol. 13, no. 3, pp. 359366, 1973.

[3] N. N. Pascu, "An improvement of Becker's univalence criterion," in Proceedings of the Commemorative Session Simon Stoilow, pp. 43-48, Braşov, Romania, 1997.

[4] J. Becker, "Löwnersche differentialgleichung und quasikonform fortsetzbare schichte functionen," Journal für die Reine und Angewandte Mathematik, vol. 255, pp. 23-43, 1972.

[5] D. Breaz, N. Breaz, and V. Pescar, "On the univalence of a certain integral operator," Acta Universitatis Apulensis, no. 26, pp. 251256, 2011.

[6] L. F. Stanciu and D. Breaz, "Univalence criteria for two integral operators," Abstract and Applied Analysis, vol. 2012, Article ID 652858, 11 pages, 2012.

[7] D. Breaz and N. Breaz, "Univalence conditions for certain integral operators," Studia Universitatis Babeş-Bolyai, Mathematica, vol. 47, no. 2, pp. 9-15, 2002.

[8] V. Pescar and S. Owa, "Univalence of certain integral operators," Journal of Approximation Theory and Applications, vol. 2, no. 1, pp. 11-16, 2006.

[9] L. Stanciu, "The univalence conditions of some integral operators," Abstract and Applied Analysis, vol. 2012, Article ID 924645, 9 pages, 2012.

[10] N. Ularu and D. Breaz, "Univalence criterion and convexity for an integral operator," Applied Mathematics Letters, vol. 25, no. 3, pp. 658-661, 2012. 


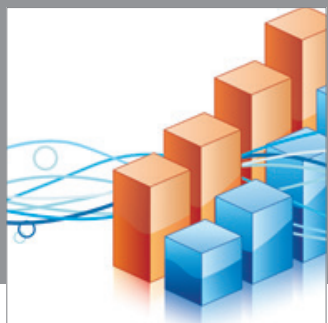

Advances in

Operations Research

mansans

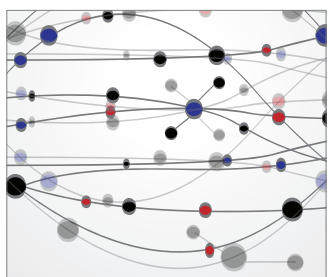

The Scientific World Journal
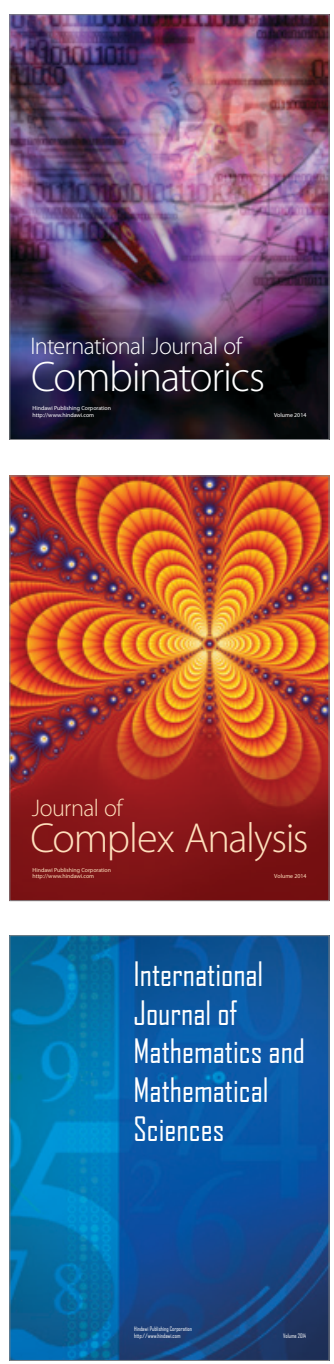
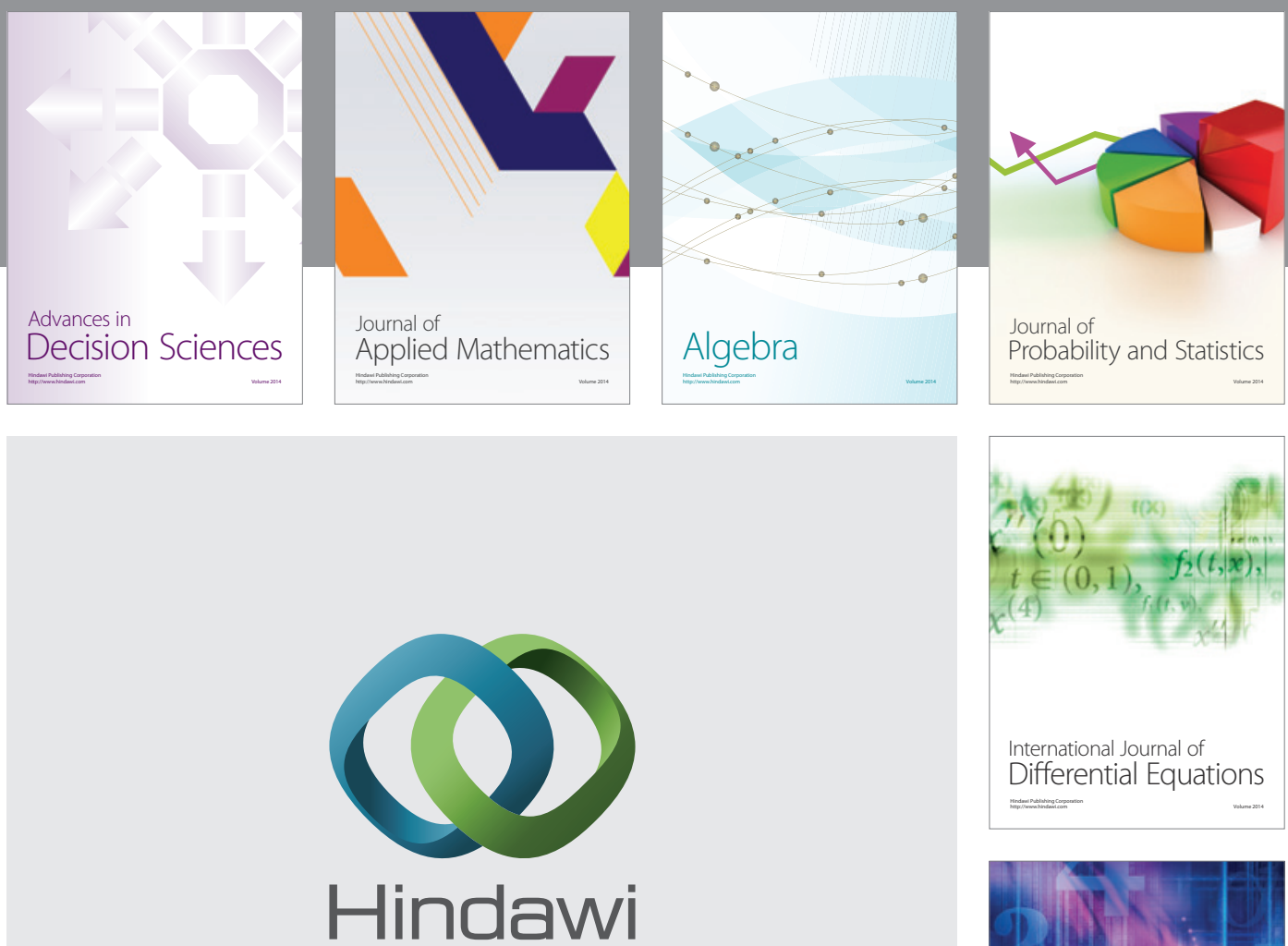

Submit your manuscripts at http://www.hindawi.com
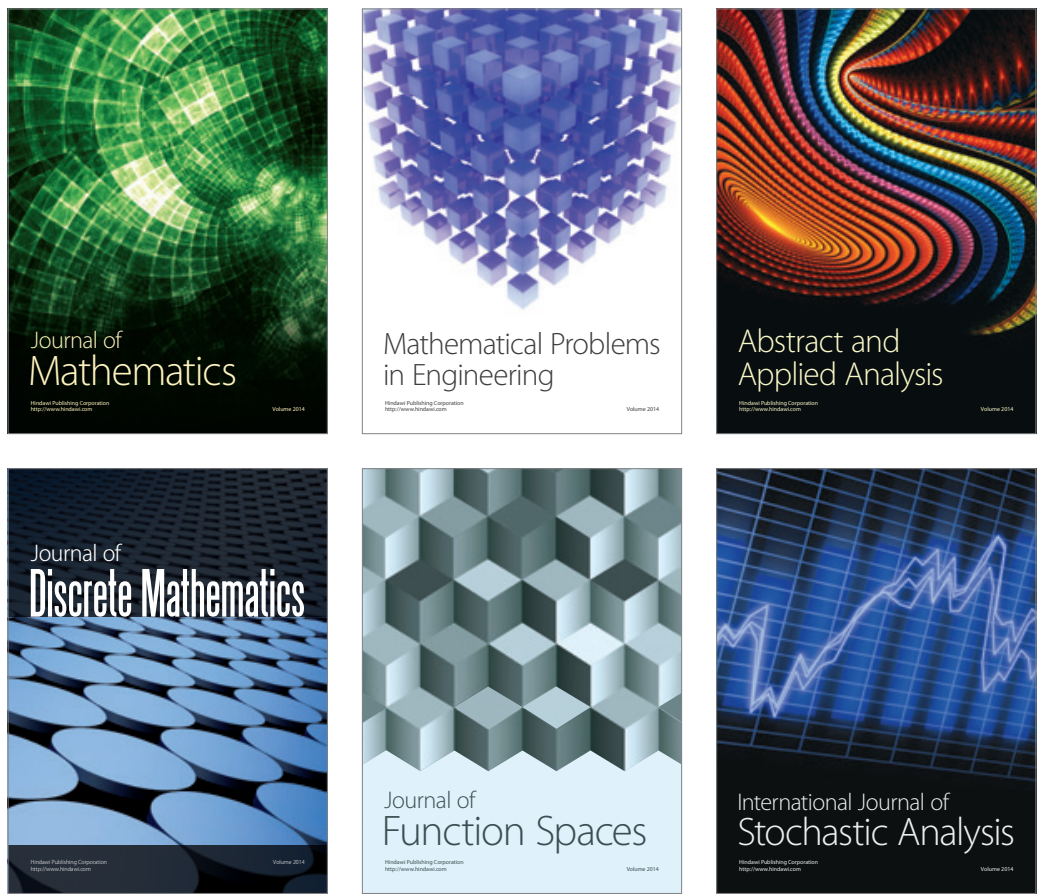

Journal of

Function Spaces

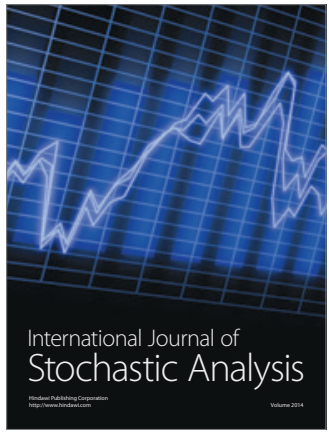

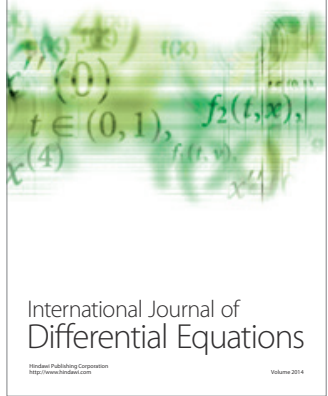
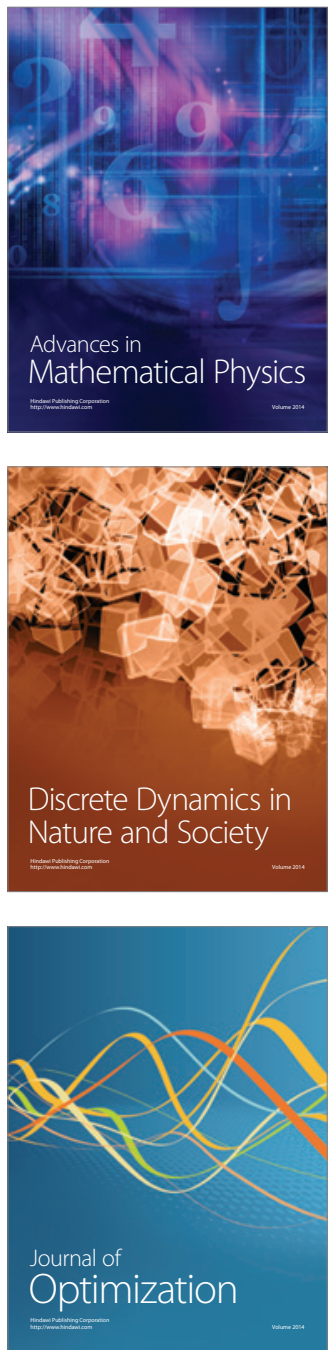